\title{
Optimization of the Rheological and Sensory Properties of Stirred Yogurt as Affected by Chemical Composition and Heat Treatment of Buffalo Milk
}

\author{
Dimitris Petridis $^{1}$, Georgia Dimitreli ${ }^{1}$, Stella Chrysalidou ${ }^{1} \&$ Pantelina Akakiadou ${ }^{1}$ \\ ${ }^{1}$ Department of Food Technology, Alexander Technological Educational Institute, Thessaloniki, Greece \\ Correspondence: Dimitris Petridis, Department of Food Technology, Alexander Technological Educational \\ Institute, Thessaloniki, Greece. E-mail: petridis@food.teithe.gr
}

Received: May 2, 2013 Accepted: September 18, 2013 Online Published: October 16, 2013

doi:10.5539/jfr.v2n6p55 URL: http://dx.doi.org/10.5539/jfr.v2n6p55

\begin{abstract}
The effects of fat content and the supplementation of milk with Sodium Caseinates (SCN) and Whey Proteins Concentrates (WPC) on the rheological and sensory properties of stirred yogurt made from buffalo milk were investigated. Whether the heat treatment of the milk affected the rheological behavior and the sensory characteristics of the samples was also evaluated. Principal Component Analysis (PCA) was used to assess in detail the relative contribution of whey proteins, caseins and fat on the rheological properties and sensory characteristics of the samples. Furthermore, it related the instrumental and objective sensory data to consumer perception (hedonic response of non-trained panelists). The objective acidity and white color intensity were positively correlated and increased with increasing casein content. Fat interacted synergistically with caseins to increase all the hedonic attributes, apart from odor. As far as rheological properties are concerned, elastic modulus $\left(G^{\prime}\right)$, instantaneous elasticity $\left(G_{g}\right)$, retarded elasticity $\left(G_{R}\right)$ and Newtonian viscosity $\left(\eta_{0}\right)$ were positively correlated with increasing casein content. However, $\tan \delta$ was negatively correlated with the aforesaid attributes and increased with increasing fat content. Whey proteins in the presence of fat determined the magnitude of flow behavior index (n). The lactic acid concentration (\%) and the b component of color (yellow color intensity) were affected positively by SCN and WPC addition but in the absence of fat. In all regression equations the effect of process temperature was found to be insignificant. Finally, the consumer-optimized composition of the fat and the added SCN can be used to formulate a marketable product.
\end{abstract}

Keywords: buffalo milk, stirred yogurt, whey protein concentrates, sodium caseinates, fat content, rheological properties, sensory properties, mixture design

\section{Introduction}

Buffalo milk is rich in proteins, fat, calcium and magnesium and has a lower concentration of cholesterol when compared to cow's (C. D. Khedkar, G. D. Khedkar, Patil, \& Kalyankar, 2003; Ahmad et al., 2008), goat's or sheep's milk (Agnihotri \& Prasad, 1993; Park, Juárez, Ramos, \& Haenlein, 2007). Furthermore, buffalo milk is a rich source of most water-soluble and fat-soluble vitamins (Khedkar et al., 2003). The high concentration of nutrients as well as various functional properties (higher emulsifying capacity, increased viscosity, higher curd tension, etc) makes buffalo milk suitable for the manufacturing of a wide range of dairy products including yogurt, butter, ice-cream and certain varieties of cheeses like Mozzarella (Khedkar et al., 2003).

Yogurt is a very popular fermented milk that is consumed all over the world (Sodini, Remeuf, Haddad, \& Corrieu, 2004), due to its high nutritional value (Tamine \& Robinson, 2007). Its classification can be made based on a variety of criteria like the chemical composition or fat content, the physical nature of the product, its flavor, or the post-fermentation processing. According to its physical nature, yogurt can be divided in two forms, set- and stirred-, with the later type being more popular (Tamine \& Robinson, 2007).

The rheological properties as well as the sensory characteristics of stirred-type yogurt are important quality parameters playing a determinant role in consumers' acceptance. Furthermore, the production of high quality products as well as their standardization can be partially fulfilled by relating the perception of texture by the consumers to the instrumental information related to this quality aspect.

Protein fortification and heat treatment are the most important parameters that determine yogurt's rheological 
properties (Damin, Alcântara, Nunes, \& Oliveira, 2009; Akalin, Unal, Dinkci, \& Hayalogut, 2012). Dry dairy ingredients such as Whey Proteins Concentrates (WPC) and Sodium Caseinates (SCN) are commonly used to increase the solids content of yogurt and thus to improve its appearance (whey separation) and physical characheristics. The addition of such ingredients increases the level of proteins in the product, enhances its hydrophilic properties and improves its viscosity (Tamine \& Robinson, 2007).

The rheological characterization of yogurt, according to Sodini et al. (2004), requires at least two kinds of measurements to define flow properties and viscoelasticity. For the determination of the flow behavior of yogurt different kinds of viscometers (Skriver, Holstborg, \& Qvist, 1999; Ramírez-Santiago, \& Vélez-Ruiz, 2013) and rheometers (Skriver et al., 1999; Lee \& Lucey, 2006; Ramirez-Santiago, Ramos-Solis, Lobato-Calleros, Pepa-Valdivia, \& Vernon-Carter, 2010) have been used. Dynamic testing rheology is an excellent tool in analyzing the viscoelastic nature of yogurt (Karoui \& De Baerdemaeker, 2007). Several researchers have used dynamic tests to evaluate the viscoelastic behavior of stirred yogurt as affected by the process variables (Skriver et al., 1999; Lee \& Lucey, 2006), the enrichment with different components (Damin et al., 2009; Ramirez-Santiago et al., 2010; Ramírez-Santiago \& Vélez-Ruiz, 2013) or the bacterial composition (Skriver et al., 1999). Besides dynamic test, creep-recovery test is a useful tool in providing information about the viscoelasticity of the material and in addition describing the nature of the bonds that predominate between the interlinked molecules of the product. However, creep analysis has not been used so far for the evaluation of the rheological behavior of yogurt.

There are few reports found in the literature concerning the study of the rheological and sensory properties of buffalo milk yogurt. Hanif, Zahoor, Iqbal, Ihsan-ul-haq and Arif (2012) studied the rheological (viscosity, hardness) and sensory (flavor, body and texture, taste, appearance) characteristics of buffalo yogurt milk as affected by the storage time and in comparison with cow milk yogurt. However, the authors did not correlate the rheological properties of the samples with the sensory perception of texture. Simanca, Andrade and Arteage (2013) evaluated the sensory acceptance of buffalo milk yogurt as affected by wheat bran addition and storage time. The effect of preservation of raw buffalo milk, by using the activation of lactoperoxidase system, on the sensory properties (texture, color, taste, flavor, overall acceptability) of the yogurt was studied by Masud, Khalid, Maqsood and Bilal (2010). However, no rheological data have been reported by any of these two research works. The aim of the present work was to study the effect of fat content, Sodium Caseinates (SCN) and Whey Proteins Concentrates (WPC) addition and heat treatment of the milk on the rheological properties and the sensory characteristics of stirred yogurt made from buffalo milk. Rheological properties were evaluated by using large (determination of the apparent viscosity) and small deformation (dynamic analysis, creep-recovery test) tests. Principal Component Analysis (PCA) was used so as to assess in detail the relative contribution of each one of the three components, as well as to relate the objective data (instrumental data and trained panelists) to consumer perception (hedonic response of non-trained panelists). Finally, a consumer-optimized combination of the three components for marketable reasons was attempted.

\section{Materials and Methods}

\subsection{Materials}

Full-fat $(7.0 \%)$ as well as skimmed $(0.3 \%)$ pasteurized and homogenized buffalo milk was purchased from a local dairy. The starter culture used was of Direct Vat Set (DVS) consisting of the microorganisms Streptococcus Thermophilus and Lactobacillus delbrueckii subsp. bulgaricus (Jointex X3, Dosi 4; CSL Centro Spermentale, de Latte S.P.A, Zelo Buon Persico, Italy). SCN (MIPRODAN 30; Arla Food Ingredients, Viby J., Denmark) and WPC (Hellenic Protein S.A., Athens, Greece) were also used for yogurt production. The composition $(\% \mathrm{w} / \mathrm{w})$ of the $\mathrm{SCN}$ was: moisture $\leq 6$; proteins $88-93.5$; fat 1.5 ; ash 4 ; lactose 0.3 . WPC had the following chemical composition: moisture $\leq 5$; proteins 80 ; fat 3.5 ; ash 3; lactose 10.4 .

\subsection{Preparation of Yogurt Samples}

Yogurt samples were prepared from full-fat (7\%), reduced-fat (5.25\%), low-fat $(1.75 \%)$ and skimmed buffalo milk. The reduced- and low-fat milk samples were prepared by mixing the full-fat with the skimmed milk. SCN and WPC were added according to the percentage mixture combination of the experimental design (Table 1) at the following concentrations: $0 \%, 1.75 \%$ and $3.5 \%$. Each batch of milk $(1400 \mathrm{~g})$ was split into 2 equal parts and placed into 2 sterilized conical flasks that had a maximum capacity of $1 \mathrm{~L}$. SCN and WPC were added to the milk before its heat treatment. After being added to the milk, the additives were dissolved in a Grant GLS400 shaking water-bath (Grant Instruments Ltd, Cambridge, G.B.) under continuous stirring for $20 \mathrm{~min}$ at $35^{\circ} \mathrm{C}$. The milk with or without the additives was then heated at $85^{\circ} \mathrm{C}$ or $95^{\circ} \mathrm{C}$ for $10 \mathrm{~min}$, in the shaking water-bath, and cooled down at approximately $42{ }^{\circ} \mathrm{C}$. Following heat treatment, the milk was inoculated with the starter culture. 
Each conical flask $(700 \mathrm{~g})$ was inoculated with $26 \mathrm{mg}$ of the starter culture (according the instructions of the manufacturer) and placed in the shaking water-bath at $42{ }^{\circ} \mathrm{C}$ for $5 \mathrm{~min}$. The inoculated milk was then transferred into sterilized glass containers that had a maximum capacity of $1.5 \mathrm{~kg}$ (each container was filled with the content of the 2 conical flasks of each milk batch) and incubated (Cooled Incubator Series 8000, Termaks AS, Bergen, Norway) at $42{ }^{\circ} \mathrm{C}$ until the $\mathrm{pH}$ dropped to 4.6. At the end of the fermentation process yogurt samples were cooled down at $15{ }^{\circ} \mathrm{C}$ in ice water and the gel was stirred using a prototype viscometer that had a larger capacity $(1500 \mathrm{~g})$ than the one used for the determination of the apparent viscosity of the samples (section 2.5.1). Yogurt samples were gently stirred for $1 \mathrm{~min}$ at $30 \mathrm{rpm}$. Stirred yogurt was then cooled at $4{ }^{\circ} \mathrm{C}$ and stored in the refrigerator for 1 day before testing.

Table 1. Percentage mixture combinations among three design ingredients at two temperature levels

\begin{tabular}{ccccc}
\hline Treatment & Whey Proteins Concentrates & Sodium Caseinates & Fat & Temperature \\
\hline 1 & 0.00 & 0.00 & 7.00 & $85^{\circ} \mathrm{C}$ \\
2 & 3.50 & 0.00 & 3.50 & $85^{\circ} \mathrm{C}$ \\
3 & 0.00 & 3.50 & 3.50 & $85{ }^{\circ} \mathrm{C}$ \\
4 & 3.50 & 3.50 & 0.00 & $85^{\circ} \mathrm{C}$ \\
5 & 0.00 & 1.75 & 5.25 & $85^{\circ} \mathrm{C}$ \\
6 & 1.75 & 0.00 & 5.25 & $85^{\circ} \mathrm{C}$ \\
7 & 3.50 & 1.75 & 1.75 & $85{ }^{\circ} \mathrm{C}$ \\
8 & 1.75 & 3.50 & 1.75 & $85{ }^{\circ} \mathrm{C}$ \\
9 & 1.75 & 1.75 & 3.50 & $85{ }^{\circ} \mathrm{C}$ \\
10 & 0.00 & 0.00 & 7.00 & $95{ }^{\circ} \mathrm{C}$ \\
11 & 3.50 & 0.00 & 3.50 & $95{ }^{\circ} \mathrm{C}$ \\
12 & 0.00 & 3.50 & 3.50 & $95^{\circ} \mathrm{C}$ \\
13 & 3.50 & 3.50 & 0.00 & $95{ }^{\circ} \mathrm{C}$ \\
14 & 0.00 & 1.75 & 5.25 & $95{ }^{\circ} \mathrm{C}$ \\
15 & 1.75 & 0.00 & 5.25 & $95^{\circ} \mathrm{C}$ \\
16 & 3.50 & 1.75 & 1.75 & $95{ }^{\circ} \mathrm{C}$ \\
17 & 1.75 & 3.50 & 1.75 & $95{ }^{\circ} \mathrm{C}$ \\
18 & 1.75 & 1.75 & 3.50 & $95^{\circ} \mathrm{C}$ \\
\hline
\end{tabular}

\subsection{Physicochemical Analysis}

For the determination of the $\mathrm{pH}$ of the yogurt samples a GP353 ATC pH METER (EDT Instruments, Kent U.K.) was used.

The colour measurements were carried out using a tristimulus colorimeter Micro Color LMC (Dr. Bruno Lange $\mathrm{GmbH}$, Dusseldorf, Germany) according to the CIE Lab scale. The system provides the values of three color components according to the Hunter Lab format that is L (brightness), $\alpha$ (+ red to -green component) and $\mathrm{b}$ (+yellow to - blue component). Yogurt samples exhibited negative values for the $\alpha$ component and positive for the $b$.

The acidity of the yogurt samples expressed as lactic acid concentration $(\% \mathrm{w} / \mathrm{w})$ was determined by titration with a solution of N/10 sodium hydroxide using phenolphthalein as an indicator (AOAC, 2002). Fat content was determined by the Gerber method (ISO, 1976). The chemicals used for the compositional analysis were all analytical grade.

All measurements were conducted in triplicate.

\subsection{Experimental Design}

The following procedure to detect and precisely determine the texture profile of a new yogurt product was followed: 
1) Choice of a three components mixture design including one process variable. The latter is used as a factor with two levels in the experiment and not as a natural part of the mixture, but it may hopefully affect the blending properties of the mixtures.

2) A sensory testing plan adapted to the needs of the mixture design in order to improve its reliability.

3) Itemization of all those attributes that could influence the texture profile of the products and their segregation to four major variable sets: objective sensory, hedonic sensory, rheological and physicochemical, totaling 21 attributes.

Based on the above considerations a refined statistical procedure was followed including three steps:

1) PCA was applied to each variable set aiming to extract the most important variables that could adequately describe and represent the first two major axes (components). The first axis retains and explains a high percentage of the total variability, the second axis a lower percentage and so on. This technique is deemed successful when the first two axes explain a reasonable proportion of the data variability (say $>50 \%$ ). If so, then the resulting correlation coefficients (loading factors) of the variables with each axis are expected to be high $(>|0.600|)$ thus drafting meaningful effects. These axes were further used as response variables against the mixture ingredients, taken as independent variables, in order to establish substantial relationships between texture profile attributes and the chemical composition of the mixture design by using response contour plots. Thus, instead of conducting numerous equation models, as many as the variables under study, the equations generated by PCA provide a more economic modeling process by choosing only one or only two equations per variable set, while maintaining a high degree of reliability. A contour plot is the projected result of the equation modeling response on a two dimensional area (surface). In accordance with the values of the regression coefficients and the nature of the models (linear, quadratic, cubic) the regression equations provide a particular surface diagram (perigram) which is unique for each dependent variable (PCA axis) considered. Thus, desirable response values and mixture blends can be detected so creating an overall characteristic profile of the products that is confined into the functional ranges of the three selected ingredients.

2) The whole set of attributes, excluding the hedonic ones, was also reworked using PCA to detect meaningful patterns between variables of heterogeneous source.

3) The blending combinations of the three ingredients were thoroughly tested for potential relationships between structure and sensory attributes that could possibly lead to the most acceptable features reflecting particular treatments for product development.

Three components, whey proteins, caseins, and fat, were used in varying proportions to produce a buffalo milk product at two process temperature levels (process variable), $85^{\circ} \mathrm{C}$ and $95{ }^{\circ} \mathrm{C}$, according to the scheme shown in Figure 1 and the mixing combinations in Table 1. This design resulted in the following component ranges: $0-3.5 \% \mathrm{WPC}, 0-3.5 \% \mathrm{SCN}$ and $0-7 \%$ fat.

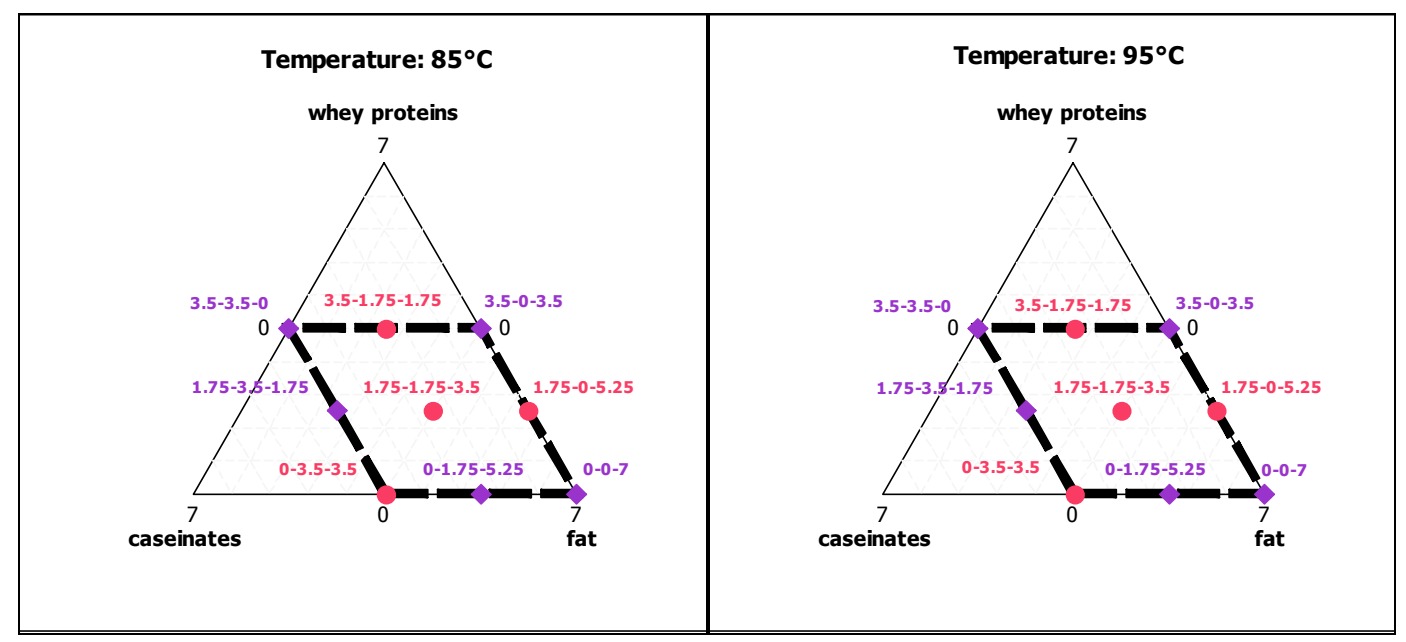

Figure 1. Mixture-amounts with extreme vertices design showing the operating area of the triangles and the points of component combinations at two temperature levels. Red circles indicate mutual reposition between the two amounts designs for the sensory assessment 
The mixture design includes 9 combined points per temperature level suggesting the selection, for sensory purposes, of the plan 9B.7 as described by Kuehl (2000) with the following notation: $t=9$ treatments, $k=4$ treatments per panelist, $b=18$ panelists, $r=8$ replicates per treatment, $\lambda=3$ pairs of similar treatments. Four randomly chosen points interchanged between the two mixture-amount levels in the sensory plan in order to facilitate equal contribution of the two temperature levels to the panelists (red circled points in Figure 1). Such designs are called Balanced Incomplete Block (BIB) designs (Kuehl, 2000) and are particularly useful when a great number of different treatments are produced and each panelist cannot evaluate so many samples in one session.

\subsection{Instrumental Design}

\subsubsection{Flow Behavior Measurements}

The flow behavior of yogurt samples was evaluated using a custom built pneumatic tube rheometer coded TR-1 Rheometer (A.T.E.I. of Thessaloniki, Greece), which has already been used for the rheological evaluation of concentrated starch solutions (Xu \& Raphaelides, 1998), processed cheese (Dimitreli \& Thomareis, 2004) and kefir (Yovanoudi, Dimitreli, Raphaelides, \& Antoniou, 2013).

The yogurt samples were placed inside the sample vessel of the viscometer, under continuous stirring (50 rpm) and the temperature was set to $20^{\circ} \mathrm{C}$. Two capillary tubes with different dimensions, attached to the bottom of the sample vessel were used for the rheological measurements. The first one had an inner diameter of $2.050 \mathrm{~mm}$ and a length of $30 \mathrm{~mm}$ and the second had dimensions of 0.975 and $35 \mathrm{~mm}$, respectively. The flow rate of the discharged fluid at the exit of the tube at varying pressures was determined so as to obtain the flow curves of the samples, that is to say the apparent viscosity as a function of the shear rate. The flow curves of the samples showed any changes to the actual values of the apparent viscosity or indicated whether the pseudoplastic behavior of the samples was affected by the different conditions. The intensive pseudoplastic behavior or the change towards a Newtonian one was evaluated by the determination of the flow behavior index (n). Rheological measurements were made in triplicate.

The sensory perception of texture can be correlated with the rheological properties related to shearing (apparent viscosity and $\mathrm{n}$ ), imitating this way the consumption of stirred yogurt from the consumers.

\subsubsection{Small Deformation Measurements}

Large deformation tests (viscosity measurements) can provide information about the structure of a material, though they cannot describe its viscoelastic behavior. This can be achieved by small deformation tests which allow the study of the chemical bonds that comprise a protein network. For the study of this kind of interaction in stirred yogurt two small deformation tests, dynamic and creep-recovery tests, were applied to the samples using a DMA rheometer (Bohlin C-VOR 150, Malvern Instruments Ltd, Worcestershire, UK).

The rheometer was equipped with a $40 \mathrm{~mm}$ diameter plate and a $4^{\circ}$ stainless steel cone. A Peltier plate system $\left(-30\right.$ to $\left.+180^{\circ} \mathrm{C}\right)$ was used for temperature control. Yogurt samples were gently mixed by stirring five times and sufficient amount was placed on the plate of the rheometer using a plastic spatula. After lowering the cone to the measuring position (the gap was set to $150 \mu \mathrm{m}$ ), the excess sample was trimmed off the edges of the cone using the spatula. Silicon oil was applied to the rim of the samples to prevent water evaporation. Rheological measurements were performed at $20^{\circ} \mathrm{C}$ in triplicate.

\subsubsection{Dynamic Test}

A frequency sweep from 0.01 to $10 \mathrm{~Hz}$ was applied to the samples at strain deformation within the linear viscoelastic region $\left(1.304 \times 10^{-5}\right)$ determined by an amplitude test. The amplitude stress sweep test was conducted at a frequency of $1 \mathrm{~Hz}$ and stresses ranged from 1 to $100 \mathrm{~Pa}$. Within the linear viscoelastic region both elastic $\left(G^{\prime}\right)$ and viscous $\left(G^{\prime \prime}\right)$ moduli are stress-independent. From the frequency sweep test the $G^{\prime}$ and $G^{\prime \prime}$ as well as the loss tangent $(\tan \delta)$ were determined. $G^{\prime}$ is a measure of the energy stored and recovered per cycle, while $\mathrm{G}^{\prime \prime}$ is a measure of the energy dissipated or lost as heat per cycle of sinusoidal deformation (Ferry, 1980). A useful parameter in describing viscoelastic behaviour is $\tan \delta$, which give a clear indication of whether the material behaves like a solid or a liquid.

\subsubsection{Creep-Recovery Test}

A stress of $0.2 \mathrm{~Pa}$ within the linear viscoelastic region (previously determined) was applied to the samples, allowing them to creep, followed by a recovery time that allowed the material to recover partly its initial structure (viscoelastic material). The duration of stress application was set to maximum $180 \mathrm{~s}$, while the instrument was programmed to automatic acceptance of steady state compliance with the provision that the 
acceptance was to be made after the steady state was achieved for $20 \mathrm{~s}$ and the creep recovery time was set to $100 \mathrm{~s}$. In all measurements the total strain values attained, ranged from $1 \times 10^{-4}$ to $1 \times 10^{-5}$ which again ensured that all samples were tested well within their linear viscoelastic limits. During these tests the instantaneous and retarded compliance as well as the Newtonian viscosity at zero shear rate $\left(\eta_{0}\right)$ were determined. The instantaneous compliance reflects the strong chemical bonds that have not been destroyed during creep or if they did destroy they reformed again instantly. The retarded compliance reflects the weak chemical bonds that have been destroyed during creep and some of them reform during recovery time. The presence of the Newtonian viscosity $\left(\eta_{0}\right)$ reveals that the inter-molecular network of a material comprises of entanglements that either remain stable (instantaneous compliance) or reform continuously (retarded compliance) until all the molecules of the network start to move (display of viscosity) due to the application of stress. The creep compliance data were given in the form of elastic moduli data (the reverse of compliance): instantaneous elasticity $\left(\mathrm{G}_{\mathrm{g}}\right)$; retarded elasticity $\left(\mathrm{G}_{\mathrm{R}}\right)$.

\subsection{Sensory Analysis}

Yogurt samples were set to equilibrium at $20{ }^{\circ} \mathrm{C}$, gently mixed by stirring five times and an amount of approximately $20 \mathrm{~g}$ was placed in special cups arranged in white plastic dishes and presented to panelists hosted in sensory booths. The order of assessment was randomized within each session. Bottled water and toast were provided to clean the palate between samples in both objective and hedonic tests.

Sensory evaluation was partitioned in two sessions, the objective and hedonic.

The objective assessment concerned perception of the intensity of an attribute and was conducted twice. Panelists were selected from the staff and research students of the Faculty. All panelists had regular previous experience of sensory testing milk products and were trained to judge various product formulations of differing textures. Eighteen panelists joined the procedure, were used four times each $(18 \times 2$ process levels $\times 2$ runs $=72)$ and were trained to assess the following sensory attributes:

- $\quad$ Odor as the typical aroma of the product ascribed mainly to acetaldehyde.

- White color intensity as the brightness.

- Acidity as the intensity of the acid flavor in the mouth.

- $\quad$ Fattiness as the fatty feeling in the mouth and gum.

- Viscosity as the perceived degree of thickness when yogurt was squeezed between tongue and the roof of the mouth and sheared during the back and forth motions of the tongue.

The hedonic assessment concerned perception of acceptability of an attribute and used panelists with no previous training or experience in sensory testing. Students from the first two semesters were selected and were taught all the definitions of attributes in order to become familiar with the concept of the experiment. They were then asked to rate the acceptability of odor, white color, fattiness, acidity and viscosity of the samples. The hedonic evaluation was conducted twice using 72 panelists.

Both sensory evaluations use the same definition of attributes (e.g. intensity of viscosity, acceptability of viscosity) following the methodology proposed by Ritzoulis, Petridis, Derlikis, Fytianos and Asteriou, 2010 and Petridis et al. 2012. By this procedure, the overall desirability of a product is substituted for by the acceptability of the attributes assigned, so establishing a direct comparison between the intensity of an attribute and its acceptance. The same attributes were also measured using instrumental methods, rheological and colorimetric, enabling each attribute to be quantitatively linked with the blending components of the mixture experiment. Overall, the hedonic and particularly the objective sensory attributes relate to specific rheological and physicochemical characteristics, which enables the degree of sensory and rheological agreement agreement to be determined, facilitates the construction of the texture profile of the products and finally permit product optimization.

Objective sensory scores per sample were checked for possible outliers using a dotplot in which values far away from the bulk of the data were removed.

Adjusted sensory mean scores of the objective and hedonic variables were calculated from the 9 samples of each run.

\subsection{Data Analysis}

Regression equations between principal major axes taken as dependent responses and the mixture components considered as independent variables were calculated according to the special cubic multiple regression equation (Piepel \& Cornell, 1994): 


$$
\begin{aligned}
& \hat{Y}=b_{1} X_{1}+b_{2} X_{2}+b_{3} X_{3}+b_{12} X_{1} X_{2}+b_{13} X_{1} X_{3}+b_{23} X_{2} X_{3}+b_{123} X_{1} X_{2} X_{3}+b_{1 \mathrm{v}} X_{1} V \\
& +b_{2 \mathrm{v}} X_{2} V+b_{3 \mathrm{v}} X_{3} V+b_{12 \mathrm{~V}} X_{1} X_{2} V+b_{13 \mathrm{~V}} X_{1} X_{3} V+b_{23 \mathrm{~V}} X_{2} X_{3} V+b_{123 \mathrm{v}} X_{1} X_{2} X_{3} V
\end{aligned}
$$

where $\mathrm{b}=$ regression coefficient, $\mathrm{X}=$ mixture component $(\mathrm{WPC}, \mathrm{SCN}$, fat) and $\mathrm{V}=$ process temperature.

Non-significant terms at 0.05 probability reference level were removed from the equations following the step-by-step backward elimination procedure. The main components were always forced to remain in the final equation form.

A regression model was considered reliable only when the lack of model fit test was not significant $(p>0.05)$, the $R^{2}$ values of the determined and predicted coefficients were reasonably high and the determined and predicted coefficients did not differ from each other by more than $20 \%$. Two replicates for the objective variables and two for the hedonic variables were extracted from the sensory experiments. Contour plots were chosen as to elucidate the mixture optimization conditions derived from the aforesaid equation.

\section{Results and Discussion}

\subsection{Principal Component Analysis}

\subsubsection{Sensory Attributes}

PCA was applied to the objective and hedonic data in order to distinguish the most important variables (Sharma, 1996). For the objective attributes, acidity and white color intensity positively form the first major axis (Table 2) which explains $38.3 \%$ of the total variation. The second axis retains $28 \%$ of data variability and is mainly represented by the viscosity in a negative direction $(r=-0.746)$. Odor and fattiness share equal coefficients between axes thus their effect is not unique. Taking into account the results from the PCA, it is possible to treat the two variables of axis 1 as a single variable. This new variable is now axis 1 and reflects responses of acidity and white color intensity. High values of axis 1 correspond to high values of acidity and white color intensity. The white color of milk, and consequently yogurt, is caused by the light scattering of fat globules and casein micelles (Walstra, Wouters, \& Geurts, 2006). Increasing the casein content causes the reflection of the light to increase presumably due to the casein aggregation, which increases the number and size of scattering particles. The increased acidity of yogurt samples is also due to the increased casein concentration. Caseins possess high buffering capacity (Salaün, Mietton, \& Gaucheron, 2005). This means that more lactic acid must be produced so as to reduce the $\mathrm{pH}$ of the samples to its final value (4.6). Therefore, an increase in the white color intensity of the samples was associated with an increase in their acidity.

Table 2. Correlation coefficients of the four attribute sets with PCA axes 1 and 2

\begin{tabular}{lrrlrr}
\hline Objective attributes & AXIS1 & AXIS2 & Hedonic attributes & AXIS1 & AXIS2 \\
\hline O-acidity & $\mathbf{0 . 7 7 4}$ & 0.433 & H-fattiness & $\mathbf{0 . 9 3 4}$ & 0.070 \\
O-odour & 0.700 & -0.611 & H-acidity & $\mathbf{0 . 9 1 4}$ & 0.197 \\
O-color & $\mathbf{0 . 6 9 4}$ & -0.062 & H-viscosity & $\mathbf{0 . 8 9 6}$ & 0.035 \\
O-fattines & 0.549 & 0.528 & H-color & $\mathbf{0 . 8 1 3}$ & 0.247 \\
O-viscosity & 0.208 & $\mathbf{- 0 . 7 4 6}$ & H-odor & 0.616 & -0.777 \\
Variance & 1.916 & 1.399 & Variance & 3.551 & 0.710 \\
Variance \% & 38.3 & 28.0 & Variance \% & 71.0 & 14.2 \\
Rheological attributes & AXIS1 & AXIS2 & Physicochemical attributes & AXIS1 & AXIS2 \\
Elastic modulus & $\mathbf{0 . 9 5 8}$ & -0.049 & Fat content & $\mathbf{- 0 . 9 7 0}$ & 0.067 \\
Newtonian viscosity & $\mathbf{0 . 9 5 0}$ & -0.108 & Lactic acid concentration & $\mathbf{0 . 9 1 9}$ & -0.039 \\
Instantaneous elasticity & $\mathbf{0 . 9 3 3}$ & 0.027 & b & $\mathbf{0 . 8 3 5}$ & 0.131 \\
Retarded elasticity & $\mathbf{0 . 9 3 3}$ & 0.080 & a & 0.580 & 0.757 \\
tan & $\mathbf{- 0 . 6 7 6}$ & -0.147 & L & -0.665 & 0.674 \\
Flow behavior index & -0.050 & $\mathbf{0 . 9 9 1}$ & & & \\
& & & Variance & 3.260 & 1.050 \\
Variance & 4.021 & 1.025 & Variance \% & 65.2 & 21.0 \\
Variance \% & 67.0 & 17.1 & & & \\
\hline
\end{tabular}

Coefficients in bold show high and unique contribution to a particular axis. Each axis explains an explicit percentage of the total variation of the data. The initial capital letters $\mathrm{O}$ and $\mathrm{H}$ denote objective and hedonic attributes, respectively. Where $\mathrm{L}, \mathrm{a}$ and $\mathrm{b}$ are the three components of color. 
All the hedonic attributes, apart from odor, describe efficiently the formation of axis 1 extracting $71 \%$ of the whole variance (Table 2). Hedonic acidity and white color intensity were positively correlated, as in the case of the objective variables.

\subsubsection{Rheological Properties}

The first axis of rheological attributes (67\% variance retention) correlates positively with $G^{\prime}, G_{R}, G_{g}$ and $\eta_{0}$ and negatively with $\tan \delta(\mathrm{r}=-0.676)$, the second axis is exclusively described by the $\mathrm{n}(\mathrm{r}=+0.991)$ explaining also another $17.1 \%$ of data variability. The increase in $\mathrm{G}^{\prime}, \mathrm{G}_{\mathrm{R}}, \mathrm{G}_{\mathrm{g}}$ and $\eta_{0}$ is due to the increased casein content of the samples, which results in increased protein-protein interactions (increased number and strength), in the presence of extra casein aggregates and in a more dense matrix. According to Sodini et al. (2004) higher protein content increases the elastic character of a gel due to the increased number of protein interactions and bonds. The bonds that comprise the protein matrix are strong secondary bonds (the casein aggregates are linked to each other with secondary bonds rather than chemical ones) like hydrogen, electrostatic and hydrophobic bonds (Lucey \& Singh, 1998). Taking into mind that $G_{g}$ reflects the strong chemical bonds and $G_{R}$ the weak chemical bonds, $G_{g}$ could be a measure for the strong secondary bonds of the matrix like hydrogen and electrostatic bonds and $G_{R}$ a measure for the weak secondary bonds like van der Waals, colloidal and hydrophobic bonds. These bonds contribute to increased elasticity and as a consequence, to reduced viscous behavior of the samples which exhibit lower values of $\tan \delta$. Furthermore, as can be seen from the flow curves of the yoghurt in Figure 2 the samples with the highest percentage of SCN addition (3.5\%) exhibited the highest values of apparent viscosity. This means that the formed aggregates have increased hydrodynamic volume, and thus an increased resistance to flow resulting in increased values of apparent viscosity and $\eta_{0}$. The heat treatment of the milk did not affect the flow curves of the samples.

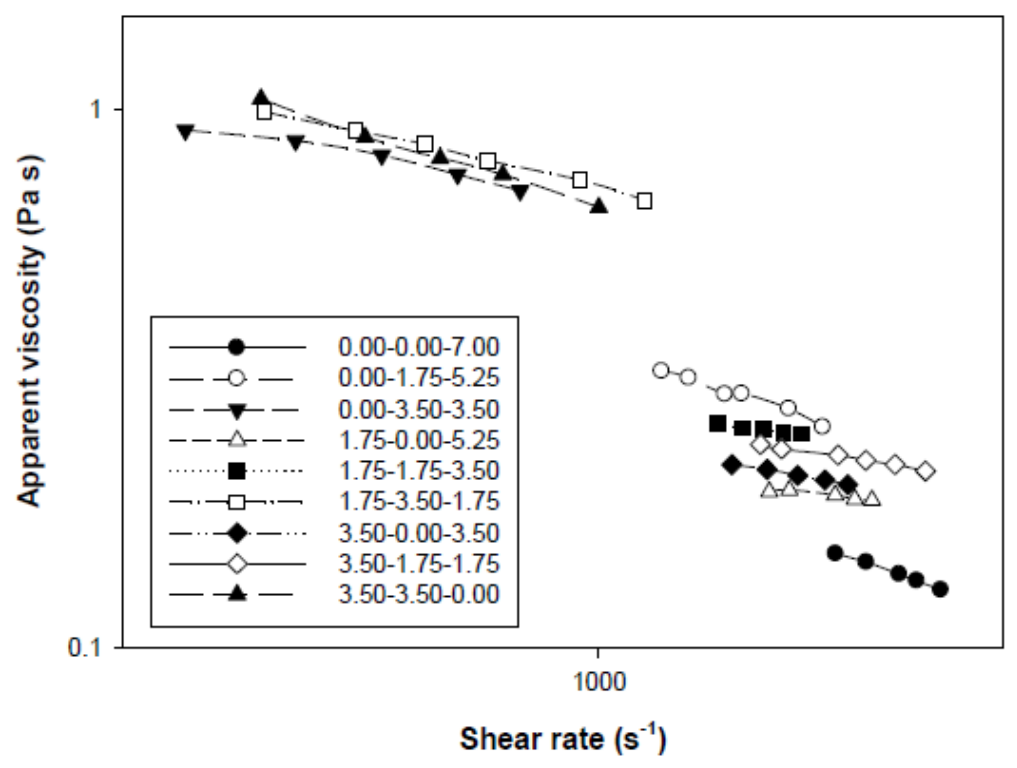

Figure 2. The flow curves of the yogurt samples. The milk for the production of the samples was heated at $85^{\circ} \mathrm{C}$ for $10 \mathrm{~min}$ (The first number indicates the percentage of Whey Proteins Concentrates, the second the percentage of Sodium Caseinates and the third one the percentage of fat)

\subsubsection{Physicochemical Properties}

The physicochemical attributes lactic acid concentration (\%) and b color component (yellow color intensity) had a strong negative effect the construction of axis $1(65.2 \%)$ whereas the fat content $(\%)$ strongly negatively $(\mathrm{r}=$ -0.970). The construction of axis is in good agreement with the characterization of the corresponding one of the objective attributes as it concerns acidity, and simultaneously is giving more information about its characterization derived from the colorimetric test. The increased values of $b$ (yellow color intensity) can be explained taking into consideration the combined effect of WPC and SCN but in the absence of fat. WPC exhibit a yellowish color due to the presence of riboflavin (Walstra et al., 2006). Fat globules and caseins causing light 
inflection result in the white color of the samples. However, caseins in the absence of fat scatter more blue light (Walstra et al., 2006), which prevails by the yellowish color of WPC. This explains the negative correlation of the fat content with the other attributes of the axis. As it concerns acidity, both whey proteins and caseins increase the buffering capacity of the system (Salaün et al., 2005) resulting in increased lactic acid concentration of the yogurt samples.

\subsection{Mixture Regression Equations}

The major components were then regressed against the three mixtures components to form specific response equations (Table 3). In all regression equations the effect of process temperature was found to be insignificant thus only a pooled mixture amounts design was drawn. This can be probably attributed to the slow rate of heating during the heat treatment of milk in the water bath. The method of heating affects the degree of whey proteins denaturation (Lucey \& Singh, 1998). When the heating rate is slow the amount of the denatured whey protein is increased, meaning that the absolute final value of heating has a secondary effect on the total amount of denatured whey proteins. In agreement with our results, Sodini et al. (2004) reported that the yogurt gel firmness was strongly related to the level of $\beta$-lactoglobulin denaturation for up to $60 \%$ denaturation. Between $60 \%$ and $90 \% \beta$-lactoglobulin denaturation, the effect of heating intensity became less evident, and no significant differences were observed above $90 \%$. Skriver et al. (1999) also found that the sensory perception of viscosity showed no differences when the milk was heated at different temperatures between $85^{\circ} \mathrm{C}$ and $90{ }^{\circ} \mathrm{C}$.

Table 3. Mixture regression equations for each attribute set. The higher the regression coefficient the greater the effect on the response variable

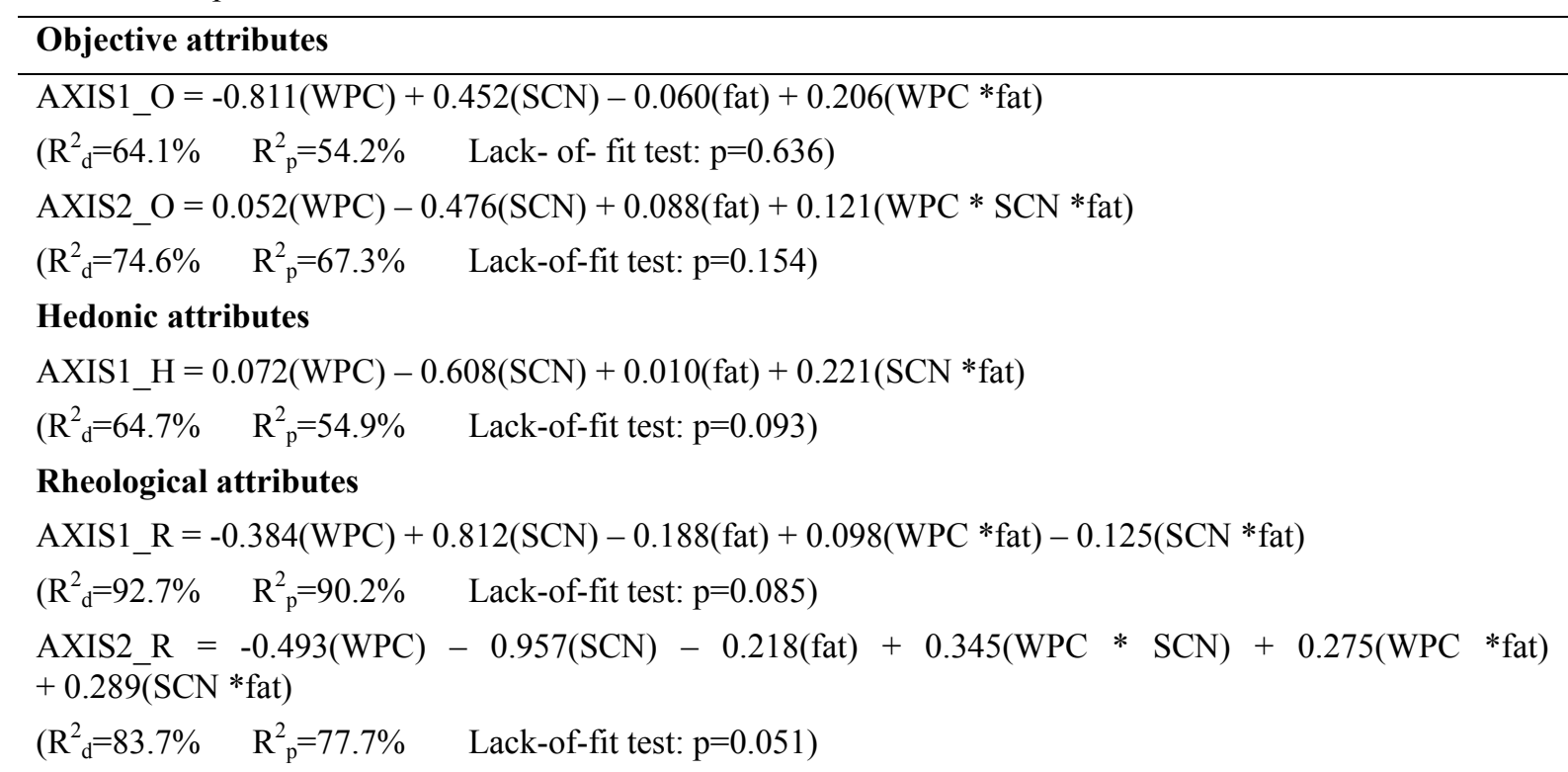

\section{Physicochemical attributes}

$$
\begin{aligned}
& \text { AXIS1_PC }=0.264(\mathrm{WPC})+0.511(\mathrm{SCN})-0.244(\mathrm{fat})-0.088(\mathrm{WPC} * \mathrm{SCN})-0.057(\mathrm{SCN} * \text { fat }) \\
& \left(\mathrm{R}_{\mathrm{d}}^{2}=97.3 \% \quad \mathrm{R}_{\mathrm{p}}^{2}=96.4 \% \quad \text { Lack-of-fit test: } \mathrm{p}=0.409\right)
\end{aligned}
$$

The ending capital letters $\mathrm{O}, \mathrm{H}, \mathrm{R}$ and $\mathrm{PC}$, denote objective, hedonic, rheological and physicochemical origin of PCA axes 1and 2, respectively. Abbreviations are as follows, WPC: Whey Proteins Concentrates, SCN: Sodium Caseinates. $\mathrm{R}_{\mathrm{d}}^{2}$ and $\mathrm{R}_{\mathrm{p}}^{2}$ denote regression coefficients of determination and prediction, respectively.

It is clearly evident from Table 3 that SCN produce the highest coefficients and thereby the greatest effect on all attributes sets apart from the objective axis 1 where WPC reveal a strong negative coefficient $(-0.81)$. This implies that the WPC increase reduces the response of AXIS1_O, that is acidity and color in the mixtures, which is mediated when fat is present (positive interactive effect, +0.206 ). The decrease in acidity with increasing WPC concentration is due to the lower buffering capacity of whey proteins when compared to caseins (Salaün et al., 2005). Furthermore, the white color of milk and subsequently yogurt, as already mentioned is the result of the light reflection of fat globules and caseins. Thus increasing the WPC addition resulted in reduced acidity and 
white color intensity of yogurt samples. The later might be due to the decrease in fat or casein content when the WPC concentration was increased. However in the presence of fat, whey proteins increase the white color intensity. In homogenized milk the native membrane is replaced largely with casein and some whey proteins (Lucey, Munro, \& Singh, 1998; Tamine \& Robinson, 2007). Denaturation of whey proteins, during milk heat treatment, complexes them with the caseins and whey proteins of the fat globule membrane (Lucey et al., 1998) resulting in increased hydrodynamic volume of the fat and consequently increased light reflection.

\subsection{Contour Plots}

The performance of all equation terms is explicitly outlined on the response contour plots of Figure 3 . The highest response of AXIS1_O (0.8-1.4 standard deviations) is confined by contour limits of WPC $0-1.6 \%$, SCN 2.4-3.5\% and fat $1.9-4.6 \%$ (Figure 3a). Obviously, caseins participate with their highest amount explaining the increased values of acidity and white color intensity, fat content exhibits medium to reduced values contributing this way to the white color intensity and whey proteins contribute minimally or not at all.
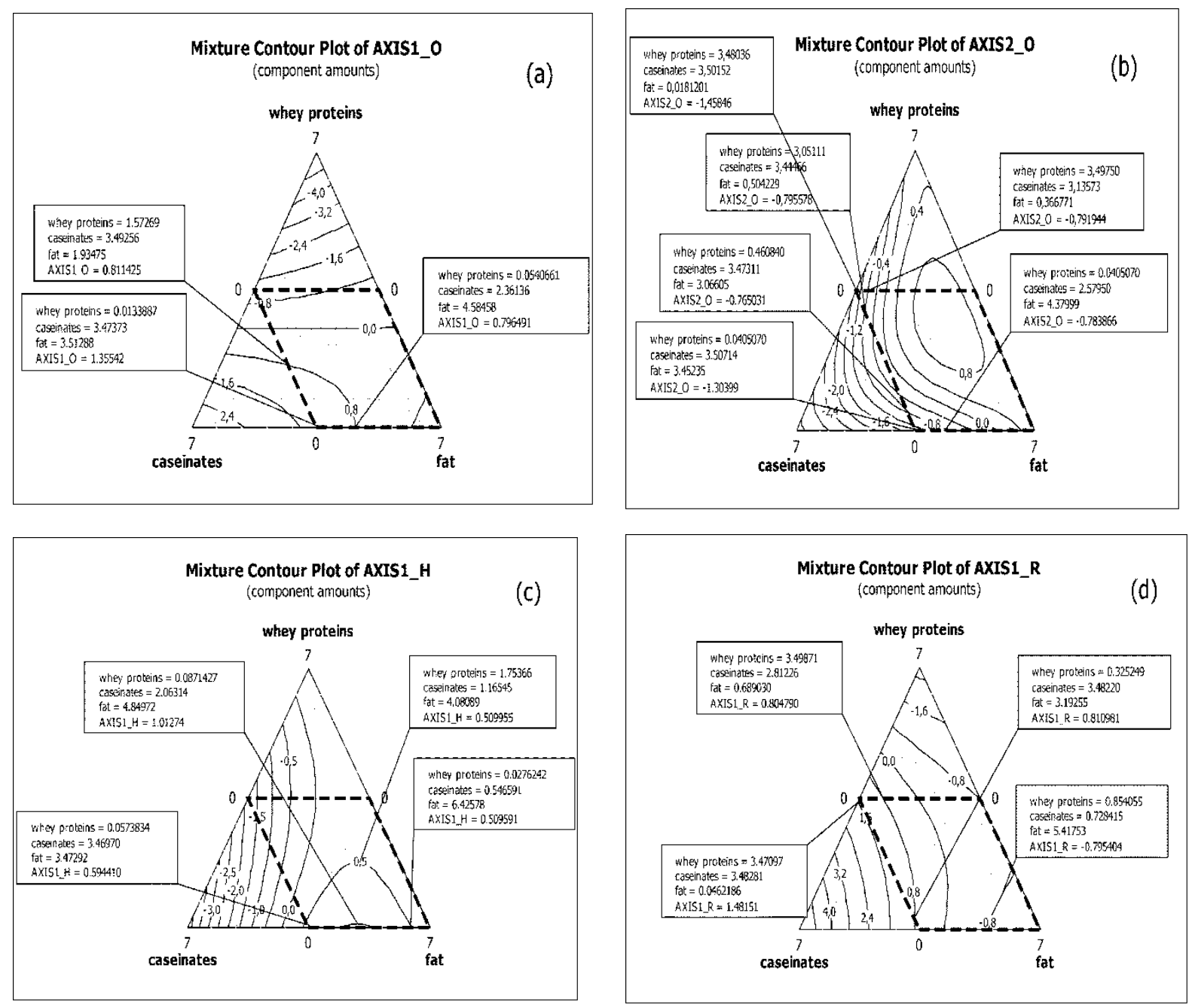

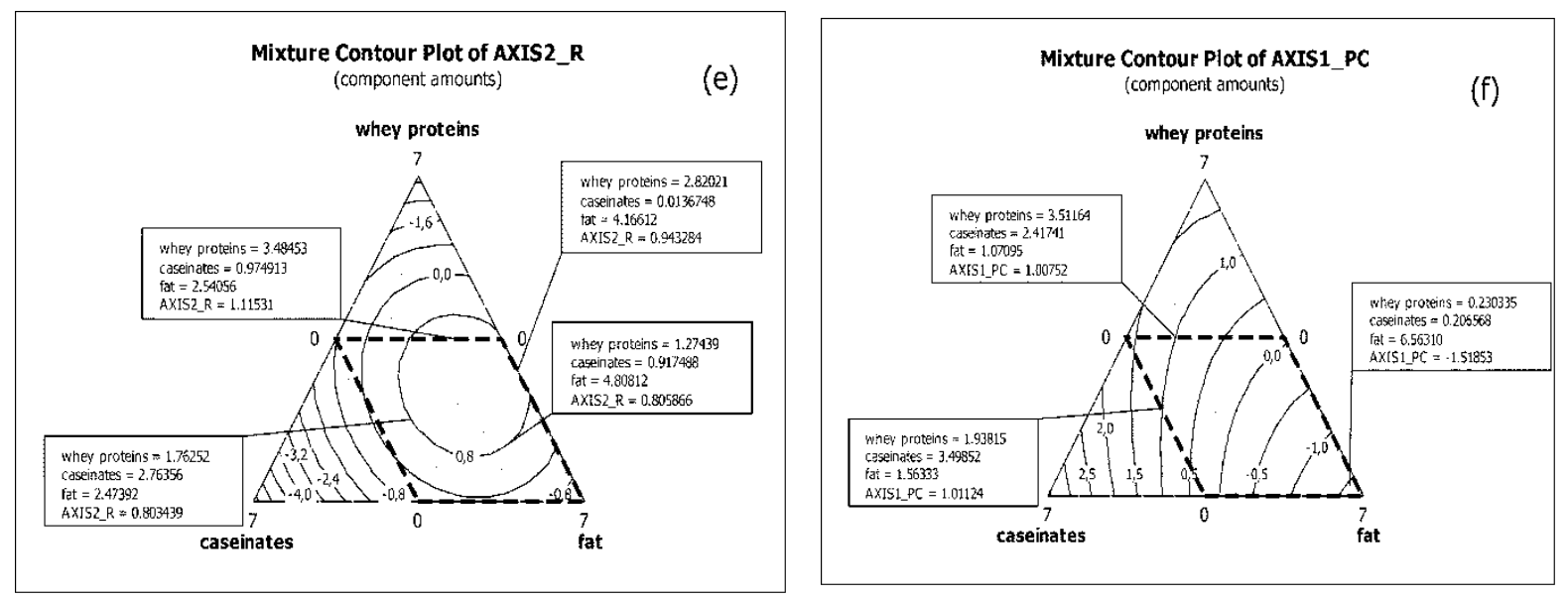

Figure 3. Contour plots of PCA axes responses for the objective (a and b), hedonic (c), rheological (d and e) and physicochemical (f) attributes of the study. The ending capital letters $\mathrm{O}, \mathrm{H}, \mathrm{R}$ and PC, denote objective, hedonic, rheological and physicochemical attributes of PCA axes 1and 2, respectively

The response of AXIS2_O (Figure 3b), which reflects viscosity, increases with SCN concentration (Table 3) because the combination of the two negative signs of component axis (Table 2) and regression coefficient produce a positive effect. Viscosity shows higher values (-0.8-(-1.0)) at two levels of WPC, $0.5 \%$ (obtuse angle between SCN and fat) and 3.5\% (oblique angle between WPC and SCN), at contour level SCN $2.6-3.5 \%$ and fat $3-4.4 \%$ (Figure $3 \mathrm{~b}$ ). As can be seen, the SCN participate with their highest amount, the fat content exhibits medium values and the effect of SCN on yogurt viscosity is more pronounced than WPC. The above are in good agreement with the findings of Akalin et al. (2012) who reported that fortification of probiotic yogurt samples with caseinates resulted in increased viscosity when compared with samples made with added WPC. This can be probably attributed to the partition of the caseins into the fat globule membrane of the homogenized milk. During milk acidification, as the isoelectric $\mathrm{pH}$ is approached and the net negative charge on casein particles it reduces the caseins on the surface of the fat globule interact with the caseins of the protein matrix, thereby incorporating the fat into the matrix and increasing the volume fraction of fat. Sodini et al. (2004) also reported increased gel firmness of yogurt samples when the fat content was increased due to the interaction of fat globule membrane and the protein matrix.

The varimax rotation of principal axes (Sharma, 1996) proved to enhance the uniqueness of attributes' effect for a particular axis. However, this technique was abandoned since it tended to generate numerous statistically significant regression terms of higher polynomial order, the interpretation of which was excessively complex.

Hedonic fattiness, acidity, viscosity and white color intensity, all positive in PCA AXIS1 (see Table 2), decline with increasing SCN concentration (Figure 3c) covering however at maximal axis response (0.5-1.0) a broad range of SCN in the contour area (0.5-3.5\%), a low WPC level (0-1.75) and a high fat content (3.5-6.4\%). It is noteworthy that fat interacts synergistically with SCN (positive regression coefficient, $(+0.221)$ increasing thereby the hedonic responses. Although increasing casein content resulted in increased viscosity, in the absence of fat the consistency of the yogurt samples was found to be crumbly, leading to reduced values of hedonic viscosity. This is a valuable indication of the necessity for the differentiation between the objective magnitude of an attribute, which is directly comparable to instrumental rheological properties, and its hedonic counterpart. However, when the increased protein content was combined with high levels of fat, the product hedonic viscosity scored high values. This can be probably attributed to the smooth consistency of the samples due to the presence of fat and its incorporation into the protein matrix. The presence of fat also increased the hedonic fattiness and white color intensity.

SCN increase the response of the rheological attributes presented by AXIS1_R (Table 3) and decrease the effect of $\tan \delta$ (due to the negative sign, see Table 2). Higher axis activity $(0.8-1.5)$ is depicted at WPC $0.3-3.5 \%$, SCN 2.8-3.5\% and fat 0-3.2\% (Figure 3d). As it can be seen SCN participate with their highest amount, while WPC and fat range from very low or zero to very high or medium values, respectively. This means that SCN in the presence of WPC or fat contribute to the increased rheological properties of AXIS1_R. The combined effect of SCN and WPC can be attributed to whey protein denaturation. Denatured whey proteins associate with casein 
micelles acting as bridging material and increasing the number and strength of bonds between protein particles (Lucey \& Singh, 1998) resulting this way in a more dense matrix with increased rheological properties. As far as the combined effect of SCN and fat is concerned is due to the incorporation of the fat into the protein matrix as already mentioned.

The $\mathrm{n}$ which forms AXIS2_R (Table 2) responds negatively to a decrease in SCN concentration (Table 3) and that result is best described at levels of WPC 1.3-3.5\%, SCN 0-2.8\% and fat 2.5-4.8\% (Figure 3e). Denatured whey proteins cover the surface of fat globules due to their interactions with the caseins of the fat globule membrane (Lucey et al., 1998), creating a "hairy" appearance. These complexes exhibit increased hydrodynamic volume due to the hydrophilic nature of whey proteins and the increased size of the unfolded denatured molecules. As a result they do not change their shape by the application of high shear rates showing this way a tendency towards Newtonian behavior (increased values of $\mathrm{n}$ ).

SCN and WPC raise the reaction of lactic acid concentration and b values (AXIS1_PC, Table 3) but lessen the effect of fat content (negative sign in AXIS1_PC, Table 2) due to their increased concentration. Highest axis values (1.0-1.6) are achieved at WPC 1.9-3.5\%, SCN 2.4-3.5\% and fat $0-1.6 \%$ (Figure 3f).

\subsection{Overall Product Profile}

To elucidate potential interrelationships among attributes of three different datasets and mixture combinations, a PCA biplot of all attributes considered in the study was drawn (Figure 4). The two major components explain $65 \%$ of the total variation of the variables (Table 4 ) and produce a synoptic view of attribute performance: a bundle of attributes on the right part of the Figure 4 identifies a strong positive correlation among rheological variables $\left(G^{\prime}, G_{R}, G_{g}\right.$ and $\eta_{0}$ ), physicochemical ones (lactic acid concentration, $\alpha$ and $b$ ) and viscosity in mixtures where fat is absent and full of WPC and SCN (3.5-3.5-0\%). Viscosity correlates strongly positively with $\mathrm{G}_{\mathrm{g}}, \eta_{0}$ and a. Caseins and whey proteins are responsible for the increased values of the mentioned rheological properties and objective viscosity. Increasing the casein content results in increased number and strength of the protein-protein interactions (strong and weak secondary bonds), increased hydrodynamic volume and consequently in increased elasticity of the protein matrix. Whey proteins participate in these interactions through their complexes with $\kappa$-casein increasing further the density and strength of the protein matrix. According to Figure 2 samples with the formulation 3.5-3.5-0\% also exhibited high values of apparent viscosity. Caseins and whey proteins increased the lactic acid concentration and in the absence of fat also increase the values of $b$ component. The increased values of $\alpha$ component (the decrease in the green color intensity due to the negative values of the component) can be attributed to the increased concentration of caseins that reduce the impact effect of WPC: green color due to the presence of riboflavin in the whey serum. Riboflavin is a yellow-green fluorescent compound, which is responsible for the color of milk serum (Fox \& McSweeney, 1998).

Table 4. Correlation coefficients between all attributes and PCA axes 1 and 2

\begin{tabular}{lll}
\hline Attributes & AXIS1 & AXIS2 \\
\hline Elastic modulus & $\mathbf{0 . 9 6 4}$ & 0.107 \\
Lactic acid concentration & $\mathbf{0 . 9 1 2}$ & -0.164 \\
Fat content & $\mathbf{- 0 . 9 0 9}$ & 0.348 \\
Newtonian viscosity & $\mathbf{0 . 9 0 9}$ & 0.295 \\
Retarded elasticity & $\mathbf{0 . 8 9 7}$ & 0.095 \\
Instantaneous elasticity & $\mathbf{0 . 8 5 7}$ & 0.309 \\
b & $\mathbf{0 . 8 0 9}$ & -0.100 \\
O-viscosity & $\mathbf{0 . 8 0 6}$ & 0.375 \\
a & $\mathbf{0 . 7 1 0}$ & 0.366 \\
tan $\delta$ & $\mathbf{- 0 . 7 0 8}$ & 0.327 \\
O-acidity & -0.230 & -0.101 \\
L & -0.423 & $\mathbf{0 . 8 0 2}$ \\
O-color & -0.432 & $\mathbf{0 . 7 0 1}$ \\
flow behaviour index & -0.012 & $\mathbf{- 0 . 6 5 7}$ \\
O-odour & 0.200 & $\mathbf{0 . 5 7 3}$ \\
O-fattines & 0.061 & -0.149 \\
Variance & 7.722 & 2.669 \\
Variance \% & 48.3 & 16.7 \\
\hline
\end{tabular}


Coefficients in bold show high and unique contribution to a particular axis. Both axes explain $65 \%$ of the total variation of the data. The capital letter $\mathrm{O}$ denotes objective sensory attributes. Where $\mathrm{L}$, $\mathrm{a}$ and $\mathrm{b}$ are the three components of color.

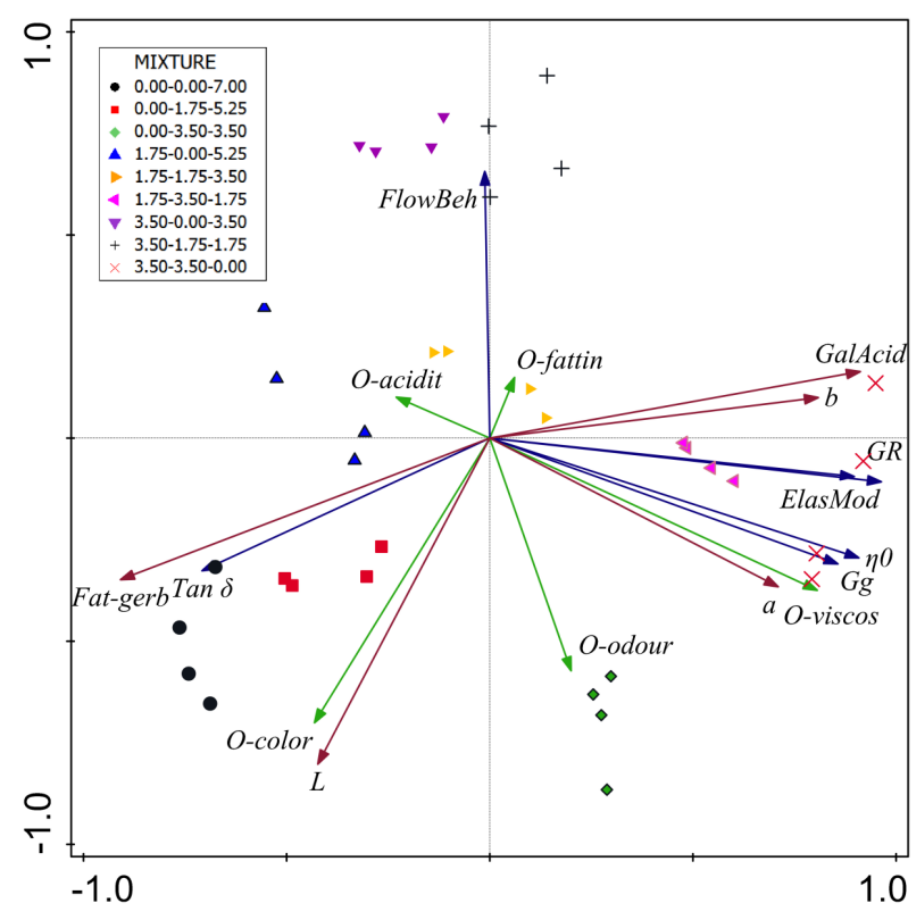

Figure 4. Biplot based on principal component analysis of sensory, rheological and physicochemical profiles at different mixture combinations (the first number indicates the percentage of Whey Proteins Concentrates (WPC), the second the percentage of Sodium Caseinates ( $\mathrm{SCN}$ ) and the third the percentage of fat) The lines indicate the approximate correlation coefficients among variables. Longer arrows denote stronger effects. A small oblique angle formed by two lines shows strong positive correlation, and a wide obtuse angle indicates strong negative correlation. The capital letter $\mathrm{O}$ denotes objective sensory attributes. Abbreviations are as follows, FlowBeh:

Flow behavior index, ElasMod: Elastic modulus, Gg: instantaneous elasticity, GR: retarded elasticity, $\eta 0$ : Newtonian viscosity, Fat-gerb: Fat content, GalAcid: Lactic acid concentration, viscos: viscosity, fattin: fattiness, acidit: acidity and finally $\mathrm{L}, \mathrm{a}$ and $\mathrm{b}$ are the three components of color

Fat content and $\tan \delta$ occupy the left part of the graph showing strong positive correlation in mixtures where fat content prevails and a negative one (obtuse angle) with the opposite bundle of attributes. The fat reduces these attributes because it disturbs the rearrangement of protein aggregates that takes place during storage (Sodini et al., 2004 ) increasing this way their viscous behavior (increased values of $\tan \delta$ ).

Mixtures rich in whey proteins and fat but low in caseins have high values of $\mathrm{n}$ (as already explained) which negatively correlates with odor and white color due to protein deficiency but fullness of SCN $(0-3.5-3.5 \%)$ and richness in fat. The white color correlates strongly positively with brightness L (objective with instrumental variable). The white color is due to the caseins and fat, while the increased values of odor are attributed to the caseins. According to Tamine and Robinson (2007) caseinates contribute to favorable aroma of yogurt.

\subsection{Optimization Procedure}

The unstructured sensory scale of 0 to $15 \mathrm{~cm}$ was further divided into five equally spaced ranks in order to facilitate a better interpretation of sensory intensity:

0-3: not at all

3-6: low

6-9: moderate 
9-12: adequate

\section{2-15: very}

The fitted values of the hedonic regression equation (AXIS1_H) were sorted in ascending order and tabulated with the corresponding values of the other attributes examined in the study. Table 5 shows the resulting attribute means and the treatments 5, 14, 3 and 12 that comply with the restriction AXIS1_H values $>0.50$ which was defined as the lower limit of acceptance in the contour plot (Figure 3c). The two mixtures are characterized by absence of WPC, a medium to maximum level of SCN and medium to high fat content. The process temperature does not influence the two mixtures which are scored as moderate to adequate intensities of objective sensory attributes. Tasters assess hedonic color and acidity as adequate and odor, fattiness and viscosity as moderate to adequate.

Table 5. Mean values of sensory (plus ranking equivalents), rheological and physicochemical attributes as assigned by the hedonic major axis 1 highest fitted scores of standard deviation $(>0.50)$

\begin{tabular}{|c|c|c|c|c|c|c|c|c|c|}
\hline Attributes & & & & & & & & & \\
\hline AXIS1_H fits & 1.020 & 1.020 & 1.020 & 1.020 & 0.616 & 0.616 & 0.616 & 0.616 & \\
\hline Treatments & 5 & 14 & 5 & 14 & 3 & 12 & 3 & 12 & \\
\hline WPC & 0.00 & 0.00 & 0.00 & 0.00 & 0.00 & 0.00 & 0.00 & 0.00 & \\
\hline $\mathrm{SCN}$ & 1.75 & 1.75 & 1.75 & 1.75 & 3.50 & 3.50 & 3.50 & 3.50 & \\
\hline Fat & 5.25 & 5.25 & 5.25 & 5.25 & 3.50 & 3.50 & 3.50 & 3.50 & \\
\hline Temperature & 85 & 95 & 85 & 95 & 95 & 85 & 95 & 85 & \\
\hline O-odour & 8.84 & 8.09 & 7.99 & 8.32 & 10.74 & 9.33 & 9.66 & 9.78 & $\begin{array}{l}\text { Intensity rank } \\
\text { moderate to adequate }\end{array}$ \\
\hline O-color & 10.96 & 11.08 & 11.34 & 10.51 & 11.92 & 10.89 & 11.02 & 11.21 & adequate \\
\hline O-acidity & 8.01 & 8.45 & 9.44 & 9.33 & 9.22 & 8.03 & 8.60 & 8.29 & moderate to adequate \\
\hline O-fattines & 8.43 & 8.44 & 9.44 & 9.03 & 9.37 & 8.60 & 9.15 & 7.70 & moderate to adequate \\
\hline O-viscosity & 8.88 & 8.61 & 9.30 & 9.25 & 11.26 & 10.33 & 10.68 & 10.62 & adequate \\
\hline H-odour & 9.63 & 8.39 & 8.52 & 8.65 & 9.88 & 8.40 & 9.02 & 8.73 & moderate to adequate \\
\hline H-color & 11.63 & 11.29 & 11.18 & 10.69 & 10.85 & 10.49 & 10.33 & 11.01 & adequate \\
\hline H-acidity & 10.92 & 10.15 & 10.09 & 9.30 & 9.80 & 8.94 & 9.47 & 8.74 & adequate \\
\hline H-fattiness & 10.18 & 9.62 & 10.30 & 10.02 & 9.97 & 8.21 & 9.85 & 8.83 & moderate to adequate \\
\hline H-viscocity & 10.32 & 9.15 & 10.30 & 9.68 & 9.59 & 6.71 & 8.88 & 8.42 & moderate to adequate \\
\hline Elastic modulus & 260 & 564 & 267 & 574 & 1224 & 1112 & 1250 & 1105 & \\
\hline $\tan \delta$ & 0.931 & 0.736 & 0.936 & 0.714 & 0.776 & 0.898 & 0.740 & 0.862 & \\
\hline Newtonian viscosity & 6710 & 7212 & 6659 & 7298 & 401230 & 390500 & 410010 & 399970 & \\
\hline Retarded elasticity & 53 & 65 & 55 & 68 & 710 & 664 & 724 & 650 & \\
\hline Instantaneous elasticity & 690 & 710 & 687 & 708 & 1398 & 1375 & 1378 & 1354 & \\
\hline Flow behavior index & 0.72 & 0.64 & 0.73 & 0.65 & 0.72 & 0.73 & 0.74 & 0.75 & \\
\hline Fat content & 4.85 & 5.15 & 5.00 & 5.10 & 3.15 & 3.10 & 3.30 & 3.10 & \\
\hline Lactic acid concentration & 1.20 & 1.22 & 1.21 & 1.21 & 1.37 & 1.36 & 1.36 & 1.37 & \\
\hline $\mathrm{L}$ & 89.4 & 89.1 & 90.0 & 89.1 & 89.3 & 89.1 & 89.2 & 88.9 & \\
\hline $\mathrm{a}$ & -5.1 & -3.9 & -4.0 & -3.9 & -4.2 & -3.8 & -4.2 & -4.0 & \\
\hline $\mathrm{b}$ & 3.9 & 4.6 & 3.8 & 4.6 & 4.9 & 5.5 & 5.0 & 5.7 & \\
\hline
\end{tabular}

The initial capital letters $\mathrm{O}$ and $\mathrm{H}$ denote objective and hedonic attributes, respectively. The notation Axis_ $\mathrm{H}$ refers to the PCA axis 1 of the hedonic attribute set. Where $\mathrm{L}$, $\mathrm{a}$ and $\mathrm{b}$ are the three components of color. Abbreviations are as follows, WPC: Whey Proteins Concentrates, SCN: Sodium Caseinates.

In absolute values, the mixture with SCN $1.75 \%$ and fat $5.25 \%$ appears hedonically superior to the mixture $3.5 \%$ and $3.5 \%$ respectively, with lower objective intensities of viscosity and odor. The first mixture combination gives lower values of $G^{\prime}, \eta_{0}, G_{R}$ and $G_{g}$, lower lactic acid concentration and $b$ values, but higher fat content.

According to the panelists, $\mathrm{SCN}$ and fat results in the formation of products with favorable attributes. The 
absence of WPC from the two mixtures resulted in increased acidity that coincides with adequate hedonic acidity.

Tan $\delta$ was significantly $(\mathrm{p}<0.001)$ higher in samples heat treated at $85^{\circ} \mathrm{C}$ than those heat treated at $95{ }^{\circ} \mathrm{C}$. No other attributes were significantly affected by processing temperature.

\section{Conclusion}

PCA adequately assessed the contribution of whey proteins, caseins and fat to the rheological properties and sensory characteristics of stirred yogurt samples from buffalo milk. The global profile of the product was best described by the physicochemical variables, fat content (\%), lactic acid and b color component, all the rheological attributes considered in the study (elastic modulus, $\eta_{0}, \mathrm{Gg}, \mathrm{GR}, \tan \delta$ and $\mathrm{n}$ ), the objective sensory acidity, white color and viscosity, and by nearly all the hedonic sensory attributes (acceptance of fattiness, acidity, viscosity and white color). Mixture components, rheological and physicochemical characteristics were in good agreement with the objective attributes, thereby validating the panelists' sensory evaluation. SCN and fat of medium to high content (1.75-3.5\% and 3.5-5.25\% respectively) could be used to formulate a commercial stirred buffalo yogurt of marketable acceptability.

\section{Acknowlegments}

The authors wish to thanks Mr Kleona Tsakmakidi (Hellenic Protein S. A.) for the supply of the SCN and WPC as well as Jonathan Rhoades and Maria Kommata for revising the English version of the manuscript.

\section{References}

Agnihotri, M. K., \& Prasad, V. S. S. (1993). Biochemistry and processing of goat milk and milk products. Small Ruminant Research, 12, 151-170. http://dx.doi.org/10.1016/0921-4488(93)90080-2

Ahmad, S., Gaucher, I., Rousseau, F., Beaucher, E., Piot, M., Gronget, J. F., \& Gaucheron, F. (2008). Effects of acidification on physico-chemical characteristics of buffalo milk: A comparison with cows' milk. Food Chemistry, 106, 11-17. http://dx.doi.org/10.1016/j.foodchem.2007.04.021

Akalin, A. S., Unal G., Dinkci, N., \& Hayalogut, A. A. (2012). Microstructural, textural and sensory characteristics of probiotic yogurts fortified with sodium calcium caseinate or whey protein concentrate. Journal Dairy Science, 95, 3617-3628. http://dx.doi.org/10.3168/jds.2011-5297

AOAC. (2002). Official Methods of Analysis (17th Ed.). Gaithersburg, Maryland: Association of Official Analytical Chemists.

Damin, M. R., Alcântara, M. R., Nunes, A. P., \& Oliveira, M. N. (2009). Effects of milk supplementation with skim milk powder, whey protein concentrate and sodium caseinate on acidification kinetics, rheological properties and structure of nonfat stirred yogurt. LWT - Food Science and Technology, 42, 1744-1750. http://dx.doi.org/10.1016/j.lwt.2009.03.019

Dimitreli, G., \& Thomareis, A. S. (2004). Effect of temperature and chemical composition on processed cheese apparent viscosity. Journal of Food Engineering, 64, 265-271. http://dx.doi.org/10.1016/j.jfoodeng.2008.10.008

Ferry, J. D. (1980). Viscoelastic properties of polymers. New York, Chichester, Brisbane, Toronto, Singapore: John Wiley \& Sons.

Fox, P. F., \& McSweeney, P. L. H. (1998). Dairy chemistry and biochemistry. London, Weinheim, New York, Tokyo, Melbourne, Madras: Blackie Academic \& Professional.

Hanif, M. S., Zahoor, T., Iqbal, Z., Ihsan-ul-haq, \& Arif, A. M. (2012). Effect of storage on the rhological and sensory characteristics of cow and buffalo milk yogurt. Pakistan Journal of Food Sciences, 22(2), 61-70.

ISO. (1976). Milk-Determinationof fat content-(Boutyrometric routine method). ISO Standard 2446. Geneva: International Standards Organization.

Karoui, R., \& De Baerdemaeker, J. (2007). A review of the analytical methods coupled with chemometric tools for the determination of the quality and identity of dairy products. Food Chemistry, 102, 621-640. http://dx.doi.org/10.1016/j.foodchem.2006.05.042

Khedkar, C. D., Khedkar, G. D., Patil, M. R., \& Kalyankar, S. D. (2003). Encyclopedia of Food Sciences \& nutrition (2nd ed.) (pp. 705-709). Maryland: Academic Press. http://dx.doi.org/10.1016/B0-12-227055-X/00134-6

Kuehl, R.O. (2000). Design of experiments: Statistical principles of research design and analysis (2nd Ed.). New 
York, Duxbury Press.

Lee, W. J., \& Lucey, J. A. (2006). Impact of gelation conditions and structural breakdown on the physical and sensory properties of stirred yogurts. Journal of Dairy Science, 89, 2374-2385. http://dx.doi.org/10.3168/jds.S0022-0303(06)72310-4

Lucey, J. A., \& Singh, H. (1998). Formation and physical properties of acid milk gels: a review. Food Research International, 30, 529-542. http://dx.doi.org/10.1016/S0963-9969(98)00015-5

Lucey, J. A., Munro, P. A., \& Singh, H. (1998). Rheological properties and microstructure of acid milk gels as affected by fat content and heat treatment. Journal of Food Science, 63, 660-664. http://dx.doi.org/10.1111/j.1365-2621.1998.tb15807.x

Masud, T., Khalid, S., Maqsood, S., \& Bilal, A. (2010). Preservation of raw buffalo's milk by the activation of lactoperoxidase system and its effect on yogurt preparation. Journal of Food Processing and Preservation, 34, 241-254. http://dx.doi.org/10.1111/j.1745-4549.2008.00337.x

Munoz, A., \& Civille, G. V. (1998). Universal product and attribute specific scaling and development of specific lexicons in descriptive analysis. Journal of Sensory Studies, 13, 57-75. http://dx.doi.org/10.1111/j.1745-459X.1998.tb00075.x

Park, Y. W., Juárez, M., Ramos, M., \& Haenlein, G. F. W. (2007). Physico-Chemical characteristics of goat and sheep milk. Small Ruminant Research, 68, 88-113. http://dx.doi.org/10.1016/j.smallrumres.2006.09.013

Petridis, D., Ritzoulis, C., Tzivanos, I., Vlazakis, E., Derlikis, E., \& Vareltzis, P. (2012). Effect of fat volume fraction sodium caseinate and starch on the optimization of the sensory properties of frankfurter sausages. Food Science \& Nutrition, 1(1), 32-44. http://dx.doi.org/ 10.1002/fsn3.6

Piepel, F. G., \& Cornel, A. J. (1994). Mixture experiment approaches: examples discussion and recommendations. Journal of Quality and Technology, 26, 117-196.

Ramirez-Santiago, C., Ramos-Solis, L., Lobato-Calleros, C., Pepa-Valdivia, C., \& Vernon-Carter, E. J. (2010). Enrichment of stirred yogurt with soluble dietary fiber from Pachyrhizus erosus L. Urban: Effect on syneresis microstructure and rheological properties. Journal of Food Engineering, 101, 229-235. http://dx.doi.org/10.1016/j.jfoodeng.2010.06023

Ramírez-Santiago, M. O., \& Vélez-Ruiz, J. F. (2013). Physicochemical rheological and stability characterizatio of a caramel flavored yogurt. LWT-Food Science and Technology, 51, 233-241. http://dx.doi.org/10.1016/j.lwt.2012.09.014

Ritzoulis, C., Petridis, D., Derlikis, E., Fytianos, K., \& Asteriou P. (2010). Utilization of inverse water-in-oil emulsion content on the organoleptic and mechanical properties. Journal of Texture Studies, 41, 62-74. http://dx.doi.org/10.1111/j.1745-4603.2009.00213.x

Salaün, F., Mietton, B., \& Gaucheron, F. (2005). Buffering capacity of dairy products. International Dairy Journal, 15, 95-109. http://dx.doi.org/10.1016/j.idairyj.2004.06.007

Sharma, S. (1996). Applied multivariate techniques. New York: John Wiley and Sons.

Simanca, M. M., Andrade, R. D., \& Arteage, M. R. (2013). Effect of bran wheat on the physico-chemical and sensory properties of buffalo mil yogurt. Información Tecnológica, 24(1), 79-86. http://dx.doi.org/10.4067/S0718-07642013000100010

Skriver, A., Holstborg, J., \& Qvist, K. B. (1999). Relation between sensory texture analysis and rheological properties of stirred yogurt. Journal of Dairy Research, 66, 609-618. http://dx.doi.org/10.1017/S0022029999003763

Sodini, I., Remeuf, F., Haddad, S., \& Corrieu, G. (2004). The relative effect of milk base starter culture and process on yogurt texture: A review. Critical Reviews in Food Science and Nutrition, 44, 113-137. http://dx.doi.org/10.1030/10408690490424793

Tamine, A. Y., \& Robinson, R. K. (2007). Tamine and Robinson's yogurt. Science and technology (3rd ed.). Boca Raton, Boston, New York, Washington, DC: CRC Press. http://dx.doi.org/10.1533/9781845692612

Walstra, P., Wouters, J. T. M., \& Geurts, T. J. (2006). Dairy Science and Technology (2nd ed.). Boca Raton: Taylor \& Francis, CRC Press.

Xu, Z., \& Raphaelides, S. N. (1998). Flow behavior of concentrated starch dispersions using a tube rheometer of novel design. Journal of Texture Studies, 29, 1-13. http://dx.doi.org/10.1111/j.1745-4603.1998.tb00150.x 
Yovanoudi, M., Dimitreli, G., Raphaelides, S. N., \& Antoniou, K. D. (2013). Flow behavior studies of kefir type systems. Journal of Food Engineering (in press). http://dx.doi.org/10.1016/j.jfoodeng.2013.03.036

\section{Copyrights}

Copyright for this article is retained by the author(s), with first publication rights granted to the journal.

This is an open-access article distributed under the terms and conditions of the Creative Commons Attribution license (http://creativecommons.org/licenses/by/3.0/). 